\title{
Embryonic Heart Rate correlation with pregnancy outcome in women with first trimester bleeding
}

\author{
Naemat Mohamed H.ELDin Shiry \\ Department of Obstetrics and gynaecology, AL zahraa University Hospital
}

\begin{abstract}
Objective : To assess the correlation between fetal heart rate and the fate of pregnancy in women with first trimester bleeding.
\end{abstract}

\section{Methods :}

This prospective observational study included 281 consecutive women with first trimester bleeding and Singleton pregnancies. The embryonic heart rate measured at the time of first trans-vaginal scan as per protocol in our university hospital for the evaluation of pregnancy. The heart rate was classified as slow if it was fewer than 110 beats per minute. The primary outcome measure is the occurrence of spontaneous early pregnancy loss prior to 12 weeks. Other outcome measures included the occurrence of late pregnancy loss (prior to 24 weeks), gestational age at birth, and fetal weight at birth.

\section{Results :}

Embryonic heart rate at less than $110 \mathrm{bpm}$ was associated with a high likelihood of pregnancy loss. The sensitivity, specificity, positive and negative predictive value, and accuracy were $43.1 \%, 86 \%$, $40.7 \%, 87.2 \%$, and $78.2 \%$, respectively. The OR (95\% CI) of first-trimester pregnancy.

\section{Conclusion:}

embryonic heart rate can be an independent predictor of the outcome of pregnancy in women with intrauterine pregnancy complaining of first trimester bleeding.

\section{Introduction}

The advent of high-resolution transvaginal ultrasound (TVS) has remarkably changed the management of early pregnancy failure. Knowledge of the ultrasound appearances of normal early pregnancy development and a good understanding of its pitfalls are essential for the diagnosis and management of early pregnancy failure. Nonetheless, no single ultrasound measurement of the different anatomical features in the first trimester has 
been shown to have a high predictive value for determining early pregnancy outcome. Similarly, Doppler studies have failed to demonstrate abnormal blood flow indices in the first trimester uteroplacental circulation of pregnancies that subsequently end in miscarriage. Ultrasound parameters combined with maternal serum hormone levels, maternal age, obstetric history and the occurrence of vaginal bleeding have all been combined in multivariate analyses, with mixed results. TVS is considered the gold standard in the diagnosis and management of incomplete miscarriage. Expectant management of miscarriage, using ultrasound parameters to determine eligibility, could significantly reduce the number of unnecessary evacuations of the retained products of conception, depending on the criteria used. (Jauniaux et $a l ., 2005)$

The predictive value of fetal heart activity on pregnancy outcome was examined. Studies can be broadly divided into those examining fetal loss after confirmed fetal cardiac activity, and those examining fetal heart rate (FHR) in relation to outcome (Arleo et al., 2011) . Fetal heart activity is the earliest proof of a viable pregnancy and it has been documented in utero by TVS as early as 36 days' menstrual age, approximately at the time when the heart tube starts to beat (Shenker et al.,1986). Theoretically, cardiac activity should always be evident when the embryo is over $2 \mathrm{~mm}$. However, in around 5-10\% of embryos between 2 and $4 \mathrm{~mm}$ it cannot be demonstrated, although the corresponding pregnancies will have a normal outcome. From 5 to 9 weeks of gestation there is a rapid increase in the mean heart rate from 110 to 175 beats per minutes (bpm). The heart rate then gradually decreases to around $160-170$ bpm. Abnormal developmental pattern of FHR and/or bradycardia has been associated with subsequent miscarriage (Tezuka et al.,1991). Inconsistent and few reports have argued that a slow FHR at 6-8 weeks appears to be associated with subsequent fetal demise. A single observation of an abnormally slow heart rate does not necessarily indicate subsequent embryonic death, but a continuous decline of embryonic heart activity might inevitably be associated with miscarriage.(Varelas et $a l ., 2008)$

The aim of this study was to assess the correlation between fetal heart rate and the fate 
of pregnancy in women with first trimester bleeding.

\section{Methods}

This prospective observational study included 281 consecutive women with first trimester bleeding and Singleton pregnancies. gestational age (calculated from the first day of the last menstrual period) of 6-12 weeks; vaginal bleeding in the preceding 24 hours, except for spotting; and a visible intrauterine gestation sac with a living embryo, verified by cardiac activity visualized on real-time ultrasound. Exclusion criteria were as follows: any uterine pathology such as myomas or malformations; loss to follow-up; and a vaginal or cervical lesion visualized on clinical examination that could explain the vaginal bleeding.

The embryonic heart rate measured at the time of first trans-vaginal scan as per protocol in our university hospital for the evaluation of pregnancy. The heart rate was labeled slow if it was less than 110 beats per minute. All patients were evaluated by transvaginal

ultrasound (GE Medical Corp.) equipped with a real-time, 5-MHz sector electronic array examinations were performed by a single investigator.
All pregnant women who presented to our antenatal clinic with vaginal bleeding during the first trimester of pregnancy were recruited. Inclusion criteria were as follows: singleton pregnancy; unremarkable medical history; a positive urinary pregnancy test result; endovaginal probe. The endovaginal probe was inserted gently into the vagina, and the uterus and adnexal regions were scanned. The intrauterine gestational sac and embryo were identified, and the embryo crown rump length was measured to confirm the gestational age. If there was a difference of 3 days between the gestational age calculated by the last menstrual period and that estimated by the crown-rump length, we considered the latter to be the accurate gestational age. Cardiac activity was noted for every embryo. After embryo heart activity was confirmed, the fetal heart rate was measured by M-mode in all cases. The calculation of the heart rate was made by measuring the time interval for at least three waves, which provided the number of heart beats per minute. The heart rate was then recorded and used for statistical analysis. All

The primary outcome measure is the occurrence of spontaneous early pregnancy 
loss prior to 12 weeks. Other outcome measures included the occurrence of late pregnancy loss (prior to 24 weeks), gestational age at birth, and fetal weight at birth

weeks a US scan demonstrated that cardiac activity was no longer present.

We analyzed data to assess whether fetal heart rate was an independent predictor of fetal loss in the first-trimester. Statistical analysis was conducted by SPSS software (version 15). Results were considered statistically significant for $\mathrm{P}$ values of less than 0.05 .

Two hundred eight one pregnant women with the first-trimester vaginal bleeding with live embryos were recruited to this study. The mean maternal age was $28.04 \pm 4.82$ years (range, 22-39 years). The mean gravida was $2.32 \pm 1.96$. The mean gestational age at ultrasound examination was $8.10 \pm 1.82$ weeks (range, 7-12 weeks). The mean fetal heart rate was $166.7 \pm 39.8 \mathrm{bpm}$ (range, 76190 bpm). Most fetal heart rates (40.9\%) were between 170 and $189 \mathrm{bpm}$.

Among the 281 pregnancies with known outcome, 51 cases had spontaneous abortion The likelihood ratio for a positive and a negative test are shown in Table 1 and depicted in $\quad$ Figure $\quad 1$.
Follow-up was done as per hospital protocol by the study contributors. The first-trimester outcome was recorded as "demise" if by 13.0

\section{Results}

There were 281 consecutive pregnancies with first trimester bleeding in which a heart rate was recorded on initial US scan. Firsttrimester outcome was known for all pregnancies.

with no anomaly. Thirty five cases had spontaneous miscarriage before 12 weeks of gestation (mean, $10.52 \pm 0.54$ weeks) and 16 cases had spontaneous miscarriage after 12 weeks of gestation (range, 14-20 weeks). Fourteen women had preterm delivery, and the remaining 216 women delivered at term. None had congenital anomaly or perinatal death.

Fetal heart rate $<110 \mathrm{bpm}$ was associated with a high likelihood of pregnancy loss. The sensitivity, specificity, positive and negative predictive value, and accuracy were $43.1 \%$, $86 \%, 40.7 \%, 87.2 \%$, and $78.2 \%$, respectively. 
Table 1 Embryonic heart rate as an independent predictor of first trimester outcome

\begin{tabular}{l|l|l|c|}
\hline & Likelihood Ratio & \multicolumn{2}{c}{ 95\% Confidence Interval } \\
\hline Positive Likelihood Ratio (+LR) & 3.09 & 4.87 & 1.88 \\
Negative Likelihood Ratio (-LR) & 0.66 & 0.51 & 0.83 \\
\hline
\end{tabular}

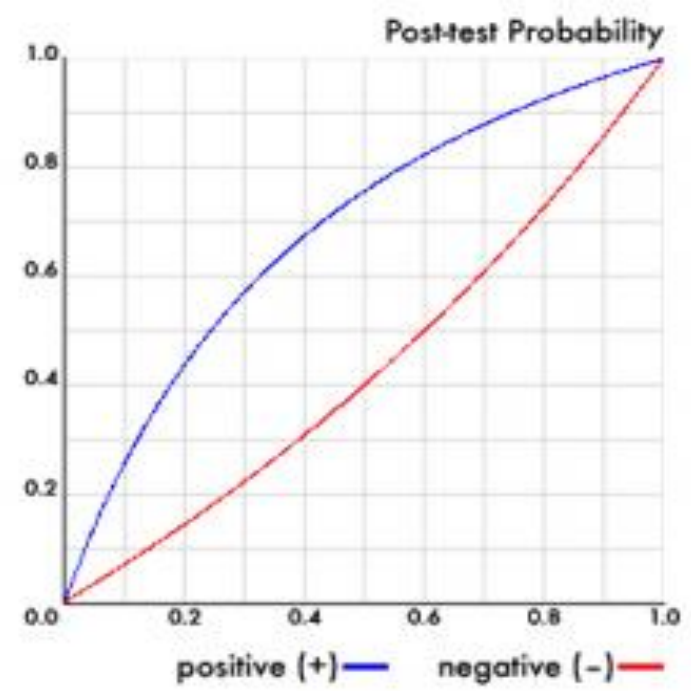

Figure 1 : The likelihood ratio of a positive and a negative test for the post-test probability of first trimester pregnancy loss

The OR (95\% CI) of first-trimester pregnancy loss was 4.67 (2.27-9.62) for pregnancies with slow heart rates at initial TVUS scan $(\mathrm{p}<0.05)$. Univariate analysis showed that heart rate was an independent predictor of first trimester pregnancy loss and fetal weight at birth.

Table (1): Shows the outcome of pregnancy by $\%$

\begin{tabular}{|l|c|c|c|}
\hline \multicolumn{1}{|c|}{ Adverse outcome } & Total No & Patients no & Percentage \\
\hline$\bullet$ Miss carrage before 12 ws gestation & 281 & 35 & $12.5 \%$ \\
\hline$\bullet$ Miss carrage after 12 ws. Gest. & 281 & 16 & $5.7 \%$ \\
\hline$\bullet$ Preterm labour & 281 & 14 & $5.0 \%$ \\
\hline
\end{tabular}

Table (2): Shows correlation coefficient $®$ of fetal bradycardia and adverse pregnancy outcome.

\begin{tabular}{|c|c|c|c|}
\hline Grade bradycardi & $\begin{array}{c}\text { Total Miss carrage } \\
\text { before 12 ws }\end{array}$ & $\begin{array}{c}\text { Miss carr. After 12 } \\
\text { ws }\end{array}$ & Preterm labor \\
\hline$<150 \mathrm{~b} / \mathrm{m}$ & $0.921^{*}$ & $0.911^{*}$ & $0.822^{* *}$ \\
\hline$<120 \mathrm{~b} / \mathrm{m}$ & $0.851^{* *}$ & $0.862^{* *}$ & $0.903^{*}$ \\
\hline$<110 \mathrm{~b} / \mathrm{m}$ & $0.854^{* *}$ & $0.832^{* *}$ & $0.925^{*}$ \\
\hline
\end{tabular}

\footnotetext{
* Statistically significant (-)ve correlation.
}

** Statistically sig. and (+)ve correlation. 
Embryonic Heart Rate correlation with pregnancy outcome...

\section{Discussion}

Earlier studies have examined the relation between a slow embryonic heart rate and the rate of first-trimester pregnancy demise, and that demise often occurs soon after the slow heart rate is detected (Doubilet et al., 2005).

In the current study, eEmbryonic heart rate at less than $110 \mathrm{bpm}$ was associated with a high likelihood of pregnancy loss. The sensitivity, specificity, positive and negative predictive value, and accuracy were $43.1 \%$, $86 \%, 40.7 \%, 87.2 \%$, and $78.2 \%$, respectively. The OR (95\% CI) of first-trimester pregnancy loss was 4.67 (2.27-9.62) for pregnancies with heart rates of less than 110 at initial TVUS scan. The results of our study confirm that fetal demise tends to occur well before the end of the first trimester; in our study, most of the spontaneous miscarriages occurred before 12 weeks of gestation. The normally slower heart rate may be due to immaturity of the sinoatrial node early on or the atrial pacemaker may actually be slower in early gestation. The mechanism of the slow fetal heart rate is unclear but may represent idioventricular rates of the abnormal heart.

If demise does occur, it is advantageous to make the diagnosis quickly to avoid the occurrence of vaginal bleeding at an inconvenient time and place and to minimize the period of concern and uncertainly for the parents. For these reasons, a follow-up US is advisable approximately 1 week after detection of a slow early-embryonic heartbeat.

If the follow-up US scan demonstrates no live embryo or fetus, the diagnosis of pregnancy demise is established. If the followup US scan demonstrated continued slow cardiac activity, further scans are warranted. If, however, the follow-up US scan demonstrates a normal heart rate, the appropriate course of action is less clear, as investigators in previous studies have not examined, to our knowledge, whether a follow-up normal heart rate negates the elevated risk of a prior slow rate this findings are similar to the study of (Merschiers et al., 1991) .

A recent study has reported that if the initial scan demonstrates a slow heartbeat, which indicates a high risk of subsequent demise, a normal heart rate on a follow-up scan obtained by 8.0 weeks lowers the risk somewhat but not entirely. (Funess et al .,1999).Specifically, in our study the risk of 
first trimester pregnancy demise was $60.6 \%$ following a slow heart rate at 6.0/7.0 weeks, and this risk decreased to $25.4 \%$ if the heart rate was normal on a follow-up scan obtained by 8.0 weeks. This latter risk, however, was over three times as high as the risk in the control group of pregnancies with a normal heart rate at 6.0-7.0 weeks and a normal rate on a follow-up scan obtained by 8.0 weeks. The incidence of pregnancy demise was elevated regardless of the timing of the initial scan (6.0-6.0 or 6.3-7.0 weeks) or the severity of the slow heart rate (moderately or very slow). Pregnancies with a borderline slow heart rate at early pregnancy had a worse outcome than those with normal heart rates at early pregnancy these results were in agreement with (Ikegawa et al., 1995). A normal follow-up heart rate after a borderline slow rate, however, was fully reassuring in that it indicated that the risk of subsequent demise in the first trimester was no longer elevated (Benson et al .,1994).

A limitation of our study is that we did not consider a per-patient analysis of subsequent hear rate. In real practice this would be the situation since many women would seek pregnancy care at another facility and a percentage of women would have a miscarriage before the second scheduled visit. In summary, when embryonic heart rate is $<110 \mathrm{bpm}$ on a initial TV US scan in women with first trimester bleeding, the likelihood of subsequent first-trimester pregnancy loss is elevated. 


\section{References}

1. Arleo EK, Troiano RN(2011 ). Outcome of early first-trimester pregnancies $(<6.1$ weeks $)$ with slow embryonic heart rate. AJR Am J Roentgenol.; 197(1):252-5.

2. Benson CB, Doubilet PM(1994). Slow embryonic heart rate in early first trimester: indicator of poor pregnancy outcome. Radiology.;192(2):343-4.

3.Doubilet PM, Benson CB(1995). Embryonic heart rate in the early first trimester: what rate is normal? J Ultrasound Med.;14(6):431-4.

4.Doubilet PM, Benson CB, Chow JS(1999). Longterm prognosis of pregnancies complicated by slow embryonic heart rates in the early first trimester. J Ultrasound Med.;18(8):537-41.

5.Doubilet PM, Benson CB(2005). Outcome of first-trimester pregnancies with slow embryonic heart rate at 6-7 weeks gestation and normal heart rate by 8 weeks at US. Radiology.;236(2):643-6.

6.Furness ME. Slow embryonic heart rates(1999). J Ultrasound Med.;18(12):818.

7. Hamela-Olkowska A, Wiech K, Jalinik K, Zaryjewski D, Kornatowski L, Dangel J(2009). [Evaluation of the embryonic and foetal heart rate at $6(+0)$ to $11(+6)$ weeks of gestation]. Ginekol Pol.;80(3):188-92.

8.Hertzberg BS, Mahony BS, Bowie JD(1988). First trimester fetal cardiac activity. Sonographic documentation of a progressive early rise in heart rate. J Ultrasound Med.;7(10):573-5.
9.Ikegawa A(1995). Prediction of first-trimester miscarriage from embryonic bradycardia and embryonic growth delay. J Obstet Gynaecol.;21(6):537-44.

10. JAUNIAUX E, JOHNS J, BURTON GJ(2005). The role of ultrasound imaging in diagnosing and investigating early pregnancy failure. Ultrasound Obstet Gynecol. (25):613-24.

11.Merchiers EH, Dhont M, De Sutter PA, Beghin CJ, Vandekerckhove DA(1991). Predictive value of early embryonic cardiac activity for pregnancy outcome. Am J Obstet Gynecol.;165(1):11-4.

12. Oztekin D, Oztekin O, Aydal FI, Tinar S, Adibelli ZH(2009). Embryonic heart rate as a prognostic factor for chromosomal abnormalities. J Ultrasound Med.;28(5):609-14.

13. Shenker L, Astle C, Reed K, Anderson C(1986). Embryonic heart rates before the seventh week of pregnancy. J Reprod Med.;31(5):333-5.

14.Tannirandorn Y, Sangsawang S, Manotaya S, Uerpairojkit B, Samritpradit P, Charoenvidhya $\mathrm{D}$ (2003). Fetal loss in threatened abortion after embryonic/fetal heart activity. Int J Gynaecol Obstet.;81(3):263-6.

15.Tezuka N, Sato S, Kanasugi H, Hiroi M(1991). Embryonic heart rates: development in early first trimester and clinical evaluation. Gynecol Obstet Invest.;32(4):210-2.

16. Varelas FK, Prapas NM, Liang RI, Prapas IM, Makedos GA(2008). Yolk sac size and embryonic heart rate as prognostic factors of first trimester pregnancy outcome. Eur J Obstet Gynecol Reprod Biol.;138(1):10-3. 


\section{علاقة معدل ضربات قلب الجنين بناتج الحمل في حالات النزيف أثناء الثلث الأول من

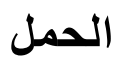 \\ د. العت محمد حفي الاين شيري}

مدرس أمراض النساء والتوليب كلية الطب جامعة الأزهر بنات

\section{الغرض من هذه الدراسة:}

هو تقييم العلاقة بين معدل ضربات قلب الجنين وناتج الحمل في السيدات اللاتي يصبن نزيف في الثلث الأول من الحمل. شملت الدراسة 281 سيدة أصبن بنزيف في التلث الأول من الحمل المنفرد ، وقد تم قياس دقات قلب الجنين أثناء إجراء الفحص بالموجات فوق الصوتية عن طريق المهبل في الثلث الأول من الحمل كما هو متبع في الوحدة. وذلك لتقييم الحمل وتم تصنيف معدل ضربات القلب أقل من 110 دقة في الدقيقة على أنه ( بطيء ). وتم قياس الناتج الأولي على أنه حدوث إجهاض تلقائي قبل الأسبوع الثاني عشر من الحمل. الناتج الآخر شمل حدوث فقدان للحمل قبل الأسبوع الرابع و العشرين من الحمل وكذلك وزن الجنين أثناء الو لادة.

ارتبط معدل دقات قلب الجنين أقل من 110 دقة في الدقيقة بزيادة في معدل فقدان الجنين.

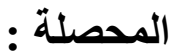

معدل دقات قلب الجنين قد يكون متتبأ مستقل لناتج الحمل في السيدات اللاتي يعانين من نزيف رحمي في التلث الأول من 